\title{
Negatively assorted gamete fertilization for supernumerary heterochromatin in two grasshopper species
}

\author{
M. D. LÓPEZ-LEÓN, J. CABRERO \& J. P. M. CAMACHO* \\ Departamento de Genética, Facultad de Ciencias, Universidad de Granada, E-18071 Granada, Spain
}

\begin{abstract}
The analysis of controlled crosses and gravid females in two grasshopper species has shown nonrandom gamete fertilization, caused in both cases by a preference for ova and sperm to fuse with gametes carrying an allele different from their own. Such a fertilization bias was observed for a B chromosome in Eyprepocnemis plorans and a supernumerary chromosome segment on the $\mathrm{M}_{7}$ autosome in Chorthippus jacobsi. In addition, a male-biased sex ratio was observed in E. plorans among the embryo offspring produced by $1 \mathrm{~B}$ gravid females which had mated with a $1 \mathrm{~B}$ male in the field, but no sex ratio distortion was apparent in the same type of crosses performed in the laboratory. The possible causes of these distortions, and the role which negatively assorted fertilization may play upon the maintenance of these polymorphisms in natural populations, are discussed.
\end{abstract}

Keywords: B chromosomes, grasshoppers, homogamy, Mendelian segregation, preferential fertilization.

\section{Introduction}

Random gamete fertilization is a general assumption for Mendelian inheritance, as random mating is for the Hardy-Weinberg law. Exceptions to random mating have been widely described and constitute the basis for sexual selection, as noted by Darwin (1871). Few exceptions to random gamete fertilization, however, have been reported up to now, especially in animals where sperm success in fertilization seems to depend little or not at all on the genotype (Muller \& Settles, 1927; Zimmering et al., 1970). Homogamy caused by preferential fertilization, however, has been reported in a few cases of hybridization between closely related animals (Hewitt et al., 1987, 1989; Bella et al., 1992; Gregory \& Howard, 1994; Wade et al., 1994). In plants, however, the pollen-tube growth velocity could play a significant role in competition between pollen grains to fertilize the macrospore. Unquestionable cases of preferential fertilization have been reported in maize, specifically for B chromosomes (Roman, 1948a,b). In recent years, the concept of animal sperm genic inactivity has been challenged because many genes showing postmeiotic activity have been observed in mammalian sperm (Erickson, 1990),

*Correspondence.

(C)1996 The Genetical Society of Great Britain. some of which could be relevant during fertilization, and whose variation could be the basis for nonrandomness of this process.

Supernumerary heterochromatin constitutes the most frequent chromosomal polymorphism in natural populations of grasshoppers. It may appear in the form of additional heterochromatic chromosome segments or else as independent entities, i.e. B chromosomes. Inheritance analyses for supernumerary segments in Chorthippus jacobsi have shown Mendelian inheritance for those located on the $\mathrm{M}_{5}$ and $\mathrm{M}_{6}$ chromosomes but accumulation mechanisms in both sexes for those on the $S_{8}$ chromosome (López-León et al., 1992a). In contrast, the three most frequent types of $\mathrm{B}$ chromosome analysed in Eyprepocnemis plorans $\left(\mathrm{B}_{1}, \mathrm{~B}_{2}\right.$ and $\left.\mathrm{B}_{5}\right)$ are transmitted in a Mendelian transmission ratio (López-León et al., 1992b). The present paper reports nonrandom gamete fertilization related to the presence of a supernumerary heterochromatic segment on the $\mathrm{M}_{7}$ autosome of $C$. jacobsi and the $\mathrm{B}_{2}$ chromosome in E. plorans.

\section{Materials and methods}

Adult males and last instar nymph females of $E$. plorans were collected at Jete and Salobreña (Granada, Spain) to perform the controlled crosses 
which have been reported in previous papers (López-León et al., 1992b, 1993a,b). These crosses constitute part of the material analysed in the present report. In addition, 106 gravid females from the same populations and the embryos they produced in the laboratory were analysed, 55 of which have been included in the present analyses. Methods for obtaining embryo offspring and cytological analysis have been described in detail previously (López-León et al., 1992b, 1993a,b).

Chorthippus jacobsi specimens were collected from natural populations in the province of Granada, Spain: Los Corales (C) (between Granada and Almuñecar in the Cázulas Mountains), Beas de Granada (BG) and Vereda de la Estrella (VE) (Sierra Nevada Mountains). For methods see LópezLeón et al. (1992a).

The strategy for analysis differed for the two species. The high number of crosses analysed in $E$. plorans permitted an analysis of global tendency in respect of sex ratio or the proportion of $1 \mathrm{~B}$ offspring. Only two crosses between heterozygotes were studied in $C$. jacobsi and did not permit such an analysis; we simply tested Mendelian genotype proportions in each cross separately, by means of a simple $\chi^{2}$-test, and for the two crosses together, by a heterogeneity $\chi^{2}$-test.

Because the total number of embryos analysed in $E$. plorans differed among crosses, we worked with relative frequencies per cross instead of absolute numbers in this species, so that all crosses were given the same weight independently of sample size. The variables used for statistical analysis were the proportion of embryos possessing $1 \mathrm{~B}(1 B)$ and the proportion of male embryos (sex ratio). Mendelian segregation implies an expected value of 0.5 for these two variables in the three types of cross used

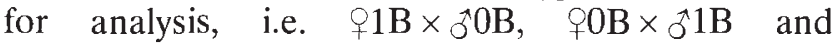
$+1 \mathrm{~B} \times 1 \mathrm{~B}$, and this will be the theoretical value employed for one-sample statistical tests. In gravid females, the proportion of eggs containing an embryo (fertil) was also analysed. A preliminary analysis using the Shapiro-Wilks test for normality showed that $1 B$ and sex ratio fitted a normal distribution in gravid females, as did sex ratio in controlled crosses, but $I B$ in controlled crosses and fertil in gravid females were not normally distributed even though many transformations were attempted (in the latter case non-normality was probably because of the fact that fertil $=1$ in the majority of females). Hence, both parametric and nonparametric tests were applied to all variables, but as their results were never contradictory for those variables which showed a normal distribution, the results for the nonparametric tests will be shown in all cases for the sake of simplicity. All statistical tests in E. plorans were performed using the BMDP statistical software (Dixon, 1990).

\section{Results}

\section{Controlled crosses in Eyprepocnemis plorans}

The one-sample Wilcoxon signed rank test showed a significant excess of $1 \mathrm{~B}$ embryos (in respect of the expected 0.5 ) in $91 \mathrm{~B} \times \jmath^{\top} 1 \mathrm{~B}$ crosses but not in the crosses in which the B was carried by one parent only (Table 1). Sex ratio, however, did not differ

Table 1 Comparison of sex ratio and the proportion of $1 \mathrm{~B}$ embryos $(1 B)$ with the values expected under Mendelian inheritance $(0.5)$, by means of one-sample Wilcoxon signed rank tests, in 53 controlled crosses performed in the laboratory with Eyprepocnemis plorans specimens

\begin{tabular}{|c|c|c|c|c|c|c|}
\hline \multirow[b]{2}{*}{ Cross type } & \multirow[b]{2}{*}{ Variable } & \multirow[b]{2}{*}{ Mean } & \multirow[b]{2}{*}{ SE } & \multirow[b]{2}{*}{$n$} & \multicolumn{2}{|c|}{$\begin{array}{l}\text { Wilcoxon signed } \\
\text { rank test }\end{array}$} \\
\hline & & & & & $T^{+}$ & $P$ \\
\hline \multirow[t]{2}{*}{$1 \mathrm{~B} q \times 0 \mathrm{~B}^{\star}$} & $1 B$ & 0.497 & 0.023 & 15 & 51.0 & 0.925 \\
\hline & sex ratio & 0.513 & 0.017 & 15 & 46.0 & 0.427 \\
\hline \multirow[t]{2}{*}{$0 \mathrm{~B}_{+} \times 1 \mathrm{~B}_{\delta}$} & $1 B$ & 0.501 & 0.018 & 11 & 32.0 & 0.929 \\
\hline & sex ratio & 0.532 & 0.022 & 11 & 16.0 & 0.131 \\
\hline \multirow[t]{2}{*}{$1 \mathrm{~B}_{+}+1 \mathrm{~B}_{0}^{*}$} & $1 B$ & 0.604 & 0.029 & 27 & 47.5 & $<0.002$ \\
\hline & sex ratio & 0.492 & 0.012 & 27 & 93.0 & 0.434 \\
\hline
\end{tabular}

Significant results are shown in bold.

$n=$ no. of crosses. 
significantly from 0.5 in any of the three types of cross.

\section{Gravid females in Eyprepocnemis plorans}

Mann-Whitney tests showed significant differences between the Jete and Salobrena populations for fertil but not for the two other variables (Table 2). A comparison of the $1 B$ and sex ratio variables with the theoretical value expected from Mendelian transmission ( 0.5 in both cases) by means of the one-sample Wilcoxon signed-rank test did not show any signi- ficant differences for these variables in crosses involving a single B-carrier, but they were significantly higher than 0.5 in $1 \mathrm{~B} \times 1 \mathrm{~B}$ crosses (Table 3 ). A comparison performed in $1 \mathrm{~B} \times 1 \mathrm{~B}$ crosses between the frequencies of $0 \mathrm{~B}$ and $2 \mathrm{~B}^{+}$embryos showed no difference between them in both controlled crosses and gravid females, which suggests that the excess of $1 \mathrm{~B}$ embryos is achieved at the expense of both $0 \mathrm{~B}$ and $2 \mathrm{~B}$ ones (Table 4).

A multiple regression analysis on the 18 $+1 \mathrm{~B} \times \jmath_{1 \mathrm{~B}}$ gravid females, using sex ratio as the dependent variable and $1 B$ and fertil as independent

Table 2 Between-population comparison for the three variables analysed in the three types of cross studied from gravid females of Eyprepocnemis plorans which had mated in the field

\begin{tabular}{|c|c|c|c|c|c|c|c|c|c|}
\hline \multirow[b]{2}{*}{ Cross type } & \multirow[b]{2}{*}{ Variable } & \multicolumn{3}{|c|}{ Jete } & \multicolumn{3}{|c|}{ Salobreña } & \multicolumn{2}{|c|}{$\begin{array}{c}\text { Mann-Whitney } \\
\text { test }\end{array}$} \\
\hline & & Mean & SE & $n$ & Mean & SE & $n$ & $U$ & $P$ \\
\hline \multirow[t]{3}{*}{$1 \mathrm{~B}_{+} \times 0 \mathrm{~B}^{\star}{ }^{\star}$} & $1 B$ & 0.427 & 0.058 & 7 & 0.467 & 0.049 & 10 & 33.0 & 0.845 \\
\hline & sex ratio & 0.556 & 0.033 & 7 & 0.495 & 0.020 & 10 & 48.5 & 0.187 \\
\hline & fertil & 1.000 & 0 & 7 & 0.945 & 0.021 & 10 & 59.5 & $<0.008$ \\
\hline \multirow[t]{3}{*}{$0 \mathrm{~B}_{+} \times 1 \mathrm{~B}^{\star}$} & $1 B$ & 0.458 & 0.028 & 7 & 0.470 & 0.043 & 13 & 42.5 & 0.812 \\
\hline & sex ratio & 0.505 & 0.031 & 7 & 0.515 & 0.014 & 13 & 43.5 & 0.874 \\
\hline & fertil & 1.000 & 0 & 7 & 0.937 & 0.031 & 13 & 66.5 & $<0.05$ \\
\hline \multirow{3}{*}{$1 \mathrm{~B}_{+} \times 1 \mathrm{~B}^{\star}$} & $I B$ & 0.578 & 0.030 & 8 & 0.566 & 0.040 & 10 & 45.0 & 0.657 \\
\hline & sex ratio & 0.573 & 0.017 & 8 & 0.535 & 0.036 & 10 & 51.0 & 0.328 \\
\hline & fertil & 1.000 & 0 & 8 & 0.956 & 0.014 & 10 & 64.0 & $<0.012$ \\
\hline
\end{tabular}

Significant results are shown in bold.

$n=$ no. of crosses.

Table 3 Comparison of sex ratio and the proportion of $1 \mathrm{~B}$ embryos $(1 B)$ with the values expected under Mendelian inheritance ( 0.5$)$, by means of one-sample Wilcoxon signed rank tests, in 55 gravid Eyprepocnemis plorans females from Jete and Salobreña which had been mated in the field

\begin{tabular}{|c|c|c|c|c|c|c|}
\hline \multirow[b]{2}{*}{ Cross type } & \multirow[b]{2}{*}{ Variable } & \multirow[b]{2}{*}{ Mean } & \multirow[b]{2}{*}{ SE } & \multirow[b]{2}{*}{$n$} & \multicolumn{2}{|c|}{$\begin{array}{l}\text { Wilcoxon signed } \\
\text { rank test }\end{array}$} \\
\hline & & & & & $T^{+}$ & $P$ \\
\hline \multirow[t]{2}{*}{$1 \mathrm{~B}_{+} \times 0 \mathrm{~B}_{\circlearrowleft}$} & $1 B$ & 0.451 & 0.036 & 17 & 47.0 & 0.163 \\
\hline & sex ratio & 0.520 & 0.019 & 17 & 43.0 & 0.334 \\
\hline \multirow[t]{2}{*}{$0 \mathrm{~B}_{+} \times 1 \mathrm{~B}_{\delta}{ }^{\wedge}$} & $1 B$ & 0.466 & 0.029 & 20 & 74.5 & 0.255 \\
\hline & sex ratio & 0.512 & 0.014 & 20 & 63.0 & 0.327 \\
\hline \multirow[t]{2}{*}{$1 \mathrm{~B}_{q} \times 1 \mathrm{~B}_{\circlearrowleft}$} & $1 B$ & 0.571 & 0.025 & 18 & 30.0 & $<0.016$ \\
\hline & sex ratio & 0.552 & 0.021 & 18 & 31.0 & $<0.032$ \\
\hline
\end{tabular}

Significant results are shown in bold.

$n=$ no. of crosses. 
Table 4 Comparison between the frequencies of $0 \mathrm{~B}$ and $2 \mathrm{~B}$ offspring from $1 \mathrm{~B} \times 1 \mathrm{~B}$ crosses in Eyprepocnemis plorans by means of two-sample Wilcoxon signed rank tests

\begin{tabular}{|c|c|c|c|c|c|c|c|c|}
\hline \multirow[b]{2}{*}{ Type of females } & \multirow[b]{2}{*}{$n$} & \multirow[b]{2}{*}{ Sex } & \multicolumn{2}{|c|}{$\begin{array}{l}\text { Frequency of } 0 \mathrm{~B} \\
\text { embryos }\end{array}$} & \multicolumn{2}{|c|}{$\begin{array}{l}\text { Frequency of } 2 \mathrm{~B} \\
\text { embryos }\end{array}$} & \multicolumn{2}{|c|}{$\begin{array}{l}\text { Wilcoxon signed } \\
\text { rank test }\end{array}$} \\
\hline & & & Mean & $\mathrm{SE}$ & Mean & $\mathrm{SE}$ & $T^{+}$ & $P$ \\
\hline \multirow[t]{3}{*}{ Controlled crosses } & 27 & $q$ & 0.194 & 0.019 & 0.201 & 0.022 & 109.0 & 0.821 \\
\hline & & ô & 0.206 & 0.023 & 0.191 & 0.024 & 126.5 & 0.726 \\
\hline & & Total & 0.200 & 0.019 & 0.196 & 0.021 & 178.5 & 0.801 \\
\hline \multirow{3}{*}{ Gravid females } & 18 & q & 0.233 & 0.024 & 0.186 & 0.026 & 47.5 & 0.169 \\
\hline & & & 0.225 & 0.024 & 0.214 & 0.020 & 63.5 & 0.816 \\
\hline & & Total & 0.229 & 0.021 & 0.200 & 0.019 & 59.0 & 0.407 \\
\hline
\end{tabular}

$n=$ no. of crosses.

Table 5 Transmission analysis for karyotypic frequencies among the progeny of two crosses between parents heterozygous (Ns) for the $\mathrm{M}_{7}$ chromosome in Chorthippus jacobsi

\begin{tabular}{|c|c|c|c|c|c|c|c|c|c|c|c|}
\hline \multirow[b]{2}{*}{ Cross } & \multicolumn{3}{|c|}{ No. of embryos } & \multirow[b]{2}{*}{ Total } & \multicolumn{4}{|c|}{$\begin{array}{l}\text { Chromosome frequencies } \\
\qquad H_{\mathrm{o}}=1: 1\end{array}$} & \multicolumn{3}{|c|}{$\begin{array}{l}\text { Karyotype frequencies } \\
\qquad H_{\mathrm{o}}=1: 2: 1\end{array}$} \\
\hline & $N N$ & Ns & ss & & $N$ & $s$ & $\chi_{1}^{2}$ & $P$ & $\chi^{2}$ & d.f. & $P$ \\
\hline $\mathrm{C} 2$ & 11 & 39 & 8 & 58 & 61 & 55 & 0.31 & 0.58 & 7.21 & 2 & $<0.05$ \\
\hline $\mathrm{BG} 2$ & 13 & 36 & 6 & 55 & 62 & 48 & 1.78 & 0.18 & 7.04 & 2 & $<0.05$ \\
\hline Total observed & 24 & 75 & 14 & 113 & 123 & 103 & 1.77 & $\begin{array}{l}0.18 \\
\chi_{2}^{2} \mathrm{acc} \\
\chi_{2}^{2} \mathrm{hc}\end{array}$ & $\begin{array}{r}\chi_{4}^{2} \text { to } \\
\text { nulate } \\
\text { roger }\end{array}$ & $\begin{array}{l}=14 . \\
=13.8 \\
=0 .\end{array}$ & $\begin{array}{l}\boldsymbol{P}<\mathbf{0 . 0 5} \\
<\mathbf{0 . 0 0 1} \\
\mathrm{P}>0.05\end{array}$ \\
\hline Total expected $(1: 2: 1)$ & 28.25 & 56.5 & 28.25 & & & & & & & & \\
\hline
\end{tabular}

Significant results are shown in bold.

variables, failed to show any significant dependence among them (ANOVA for regression: $F_{2,15}=0.19$ $P=0.827)$. Finally, a correlation analysis between fertil and the frequency of $1 \mathrm{~B}$ embryos showed no significant relationship $\left(r_{\mathrm{s}}=-0.16, \quad\right.$ d.f. $=16$, $P=0.52)$.

\section{Controlled crosses in Chorthippus jacobsi}

Normal $\mathrm{M}_{7}$ chromosomes $(N)$ showed a very small distal C-band, which was larger in segmented $\mathbf{M}_{7}$ chromosomes (s) (see Cabrero et al., 1987). In the VE1 cross the female was heterozygous $(N s)$ but the male lacked the extra segment $(N N)$. In $\mathrm{C} 2$ and BG2 crosses both parents were heterozygous. In the VE1 cross, 12 out of 26 embryo offspring analysed were $N s$ and the remaining 14 were $N N$, which was not significantly different from the 1:1 ratio expected under Mendelian segregation $\left(\chi_{1}^{2}=0.15, P=0.69\right)$. The results for the two crosses between heterozygotes showed that whereas chromosome frequencies did not differ from the 1:1 transmission ratio, the analysis of karyotype frequencies revealed a significant excess of heterozygous embryo progeny (Table $5)$.

\section{Discussion}

The excess of $1 \mathrm{~B}$ embryos in $1 \mathrm{~B} \times 1 \mathrm{~B}$ crosses in $E$. plorans cannot be related to differential egg resorption in females because in grasshoppers meiotic segregation occurs after egg laying (see López-León et al., 1992a). Neither is it the result of segregation distortion favouring the $\mathrm{B}$ in one sex but not in the other, because the frequencies of $1 \mathrm{~B}$ embryos yielded by crosses in which the B was carried by a single parent did not differ from those expected under Mendelian segregation (López-León et al., $1992 \mathrm{~b}$; this report). The surfeit of $1 \mathrm{~B}$ embryos is also not attributable to preferential death of $0 \mathrm{~B}$ and $2 \mathrm{~B}$ zygotes during early development because the frequency of 1B embryos is not correlated with fertil, 
which was very high in most gravid females. In $C$. jacobsi, the low proportion of infertile eggs (10 per cent in the $\mathrm{C} 2$ cross and 5 per cent in the BG2 cross) runs against selective zygotic death of homozygous embryos as an explanation for the significant excess of heterozygotes yielded by $N s \times N s$ crosses, because the observed deficit in homozygote frequency would imply about 25 per cent egg mortality. [Note in Table 5 that 75 heterozygotes were obtained in the two crosses. Assuming that survival was 100 per cent for heterozygotes, about 75 eggs should have contained homozygotes of which only 38 survived. This would imply a mortality rate equal to $(75-38) / 150=0.25$.] The possibility that the $s$ chromosome showed accumulation during gamete formation in one sex but elimination in the other (so that the resulting pooled transmission ratio for both sexes would be Mendelian, but the excess of heterozygotes would derive from random fertilization of distorted gametic frequencies in both sexes) cannot be completely ruled out. However, the observation that the $N s$ female in the VE1 cross (mated to an $N N$ male) yielded the two $\mathbf{M}_{7}$ chromosome types in Mendelian ratios gives little support to this hypothesis.

The most plausible hypothesis in both species, with the available data, is nonrandom gamete fertilization, and specifically, a kind of negative assortative fertilization favouring the fusion of male and female gametes differing for the markers used, i.e. the $\mathrm{B}_{2}$ chromosome in $E$. plorans and the supernumerary segment on the $\mathrm{M}_{7}$ chromosome in $C$. jacobsi. Such a process could be favoured by polyspermy, which is a relatively frequent phenomenon in hemimetabolan insects (Anderson, 1972) and has been shown to be plausible in C. jacobsi (Cabrero \& Camacho, 1985) (formerly mistaken for C. brunneus; see López-León et al., 1992a).

An alternative hypothesis, which does not necessarily depend on polyspermy, emerges from the fact that the sperm pronucleus is present in the egg when it engages in meiotic segregation, so that it is conceivable that the sperm genotype could influence meiotic segregation in the egg, e.g. favouring migration of the marker it carries towards the first polar body. The male effects on transmission ratio of the $\mathrm{B}_{2}$ chromosome through 1B females (Herrera et al., $1996)$ that we have recently observed in $E$. plorans suggest that meiotic segregation cannot be entirely under female control, thus leaving some scope for sperm effects.

The male-biased sex ratio shown by embryo offspring from $1 \mathrm{~B}$ gravid females presumably mated to $1 \mathrm{~B}$ males in the field was neither caused by differ- ential zygote mortality nor related to the excess of $1 \mathrm{~B}$ offspring (as was indicated by a multiple regression analysis). The most likely hypothesis is preferential fertilization by male-determining sperm, as in the case of the grasshopper Chorthippus parallelus (Bella et al., 1992). In the latter case a preference for homogamic fertilizations was also noted in crosses between two subspecies, a fact that had also been reported in the case of the hybrid zone in the Alpes Maritimes for other grasshopper species, e.g. Podisma pedestris (Hewitt et al., 1987, 1989). Remarkably, homogamic fertilization has been found to be responsible for postmating prezygotic reproductive isolation between closely related species in two insects, Tribolium (Wade et al., 1994) and Allonemobius (Gregory \& Howard, 1994).

In two other insect species, the ladybird Exochomus quadripustulatus and the parasitic wasp Nasonia vitripennis, a relationship between $\mathrm{B}$ chromosomes and sex ratio distortion has been reported. In $E$. quadripustulatus an analysis of 14 populations showed that the proportion of males was negatively correlated with the frequency of B chromosomes (Henderson, 1988). However, it was suggested that the Bs were not responsible in themselves for the sex ratio distortion (because it was also apparent in related species lacking $B s$ ) but that both $B$ and male frequencies in natural populations were affected by the same factors (Henderson, 1988). The B chromosome in N. vitripennis (known as Paternal Sex Ratio or PSR), on the other hand, is inherently associated with a male-biased sex ratio distortion. This forms the basis of a powerful accumulation mechanism by converting diploid (female) eggs into haploid eggs which develop into B carrying males, thus constituting an extreme example of a parasitic B chromosome (see Beukeboom \& Werren, 1993 for a review).

The most intriguing feature of $E$. plorans is that sex ratio distortion was apparent in gravid females but not in controlled crosses. Perhaps the excess of male embryos was caused by differential sperm ageing favouring male determining ones, which was facilitated in gravid females because they were maintained isolated from males in the laboratory until laying, whereas the females in controlled crosses always had an available male with which to mate, and so were continuously obtaining fresh sperm.

Although in plants it is commonly accepted that skewed segregation can arise from male gametophytic selection (see Wendel et al., 1987 for references), male gamete selection in animals is controversial because most evidence hitherto suggests genetic inactivity of spermatozoa and that 
their success in fertilization depends exclusively on the diploid genotype of the male (Zimmering et al., 1970). However, recent studies have demonstrated the existence of a number of postmeiotically expressed genes in sperm (Erickson, 1990), which opens the possibility that gamete fertilization can depend on the interaction of the genotypes of gametes.

The results in the present report, combined with those on P. pedestris (Hewitt et al., 1987, 1989) and C. parallelus (Bella et al., 1992) suggest that grasshopper gametes may combine in a nonrandom manner, which could be accomplished simply on the basis of genetically induced changes in the chemistry of fertilization. This subject clearly demands thorough investigation not only in grasshoppers but also in other insects, because nonrandom fertilization in animals might not be as rare as has been hitherto thought. Thus, for example, selective fertilization could account for the absence of certain karyotypes in natural populations of the Californian bark weevil Pissodes terminalis showing polymorphism for the C chromosome (Smith, 1962; Smith \& Takenouchi, 1962).

As a final comment, the negatively assorted gamete fertilization related to the presence of the $\mathrm{B}_{2}$ chromosome in E. plorans and the $s$ chromosome in $C$. jacobsi could help maintain these polymorphisms in natural populations by stabilizing their frequencies. This is especially interesting in E. plorans where the three most widespread $\mathrm{B}$ chromosome variants $\left(B_{1}, B_{2}\right.$ and $\left.B_{5}\right)$ lack any drive helping their maintenance in natural populations. Perhaps the excess of $1 \mathrm{~B}$ offspring yielded in $1 \mathrm{~B} \times 1 \mathrm{~B}$ crosses could produce a slight buffering effect on $B$ frequency, which may depend on the intensity of B effects on carrier fitness and random variation caused by small population size.

\section{Acknowledgements}

We are indebted to M. W. Shaw and an anonymous referee for perceptive criticism. This study was supported by grants from the Spanish D.G.I.C.Y.T. (PB93-1108) and Plan Andaluz de Investigación (Grupo no. 3122).

\section{References}

ANDERSON, D. T. 1972. The development of hemimetabolous insects. In: Counce, S. J. and Waddington, C. H. (eds) Developmental Systems: Insects, Vol. 1, pp. 95-163. Academic Press, London.
BELLA, J. L., BUTLIN, R. K., FERRIS, C. AND HEWITT, G. M. 1992. Asymmetrical homogamy and unequal sex ratio from reciprocal mating-order crosses between Chorthippus parallelus subspecies. Heredity, 68, 345-352.

BEUKeBoom, L. W. AND WERREN, J. H. 1993. Transmission and expression of the parasitic paternal sex ratio (PSR) chromosome. Heredity, 70, 437-443.

CABrero, J. AND CAMACHO, J. P. M. 1985. Cytological evidence for either polyspermy or polar-body activation in mosaic embryos of Chorthippus brunneus (Orthoptera, Acrididae). Genetica, 66, 81-84.

CABrero, J, Alché, J. D. AND CAMACho, J. P. M. 1987. A test for equilocality of supernumerary heterochromatin distribution in grasshoppers. Genome, 29, 110-115.

DARwin, c. 1871. The Descent of Man, and Selection in Relation to Sex. Appelton, New York.

DIXON, w. J. (ed.) 1990. BMDP Statistical Software Manual. University of California Press, Berkeley, CA.

ERICKSON, R. 1990. Post-meiotic gene expression. Trends Genet., 6, 264-269.

GREGORY, P. G. AND HOWARD, D. J. 1994. A postinsemination barrier to fertilization isolates two closely related ground crickets. Evolution, 48, 705-710.

HENDERSON, s. 1988. A correlation between B chromosome frequency and sex ratio in Exochomus quadripustulatus. Chromosoma, 96, 376-381.

HerRera, J. A., LóPEZ-LEÓN, M. D., CABrero, J., SHAw, M. W. AND CAMACHO, J. P. M. 1996. Evidence for B chromosome drive suppression in the grasshopper Eyprepocnemis plorans. Heredity, 76, 633-639.

HEWITT, G. M., NICHOLS, R. A. AND BARTON, N. 1987. Homogamy in a hybrid zone in the alpine grasshopper Podisma pedestris. Heredity, 59, 457-466.

HEWITT, G. M., MASON, P. AND NICHOLS, R. A. 1989. Sperm precedence and homogamy across a hybrid zone in the alpine grasshopper Podisma pedestris. Heredity, 62, $343-353$.

LÓPEZ-LEÓN, M. D., CABRERO, J. AND CAMACHO, J. P. M. 1992a. Male and female segregation distortion for heterochromatic supernumerary segments on the $\mathrm{S}_{8}$ chromosome of the grasshopper Chorthippus jacobsi. Chromosoma, 101, 511-516.

LÓPEZ-LEÓN, M. D., CABRERO, J., CAMACHO, J. P. M., CANO, M. I. AND SANTOS, J. L. 1992b. A widespread B chromosome polymorphism maintained without apparent drive. Evolution, 46, 529-539.

LÓPEZ-LEÓN, M. D., CABRERo, J., PARDo, M. C., VISERAS, E. AND CAMACHO, J. P. M. 1993a. Paternity displacement in the grasshopper Eyprepocnemis plorans. Heredity, 71, $539-545$.

LÓPEZ-LEÓN, M. D., CABRERo, J., PARDo, M. C., ViSERAS, E., CAMACHO, J. P. M. AND SANTOS, J. L. 1993b. Generating high variability of $\mathrm{B}$ chromosomes in Eyprepocnemis plorans (grasshopper). Heredity, 71, 352-362.

MULLER, H. J. AND SETTLES, F. 1927. The non-functioning of the genes in spermatozoa. Z. Indukt. Abst. Vereb. Lehre., 43, 285-312.

ROMAN, H. 1948a. Selective fertilization in maize. Genetics, 33, 122.

(C) The Genetical Society of Great Britain, Heredity, 76, 651-657. 
Roman, H. 1948b. Directed fertilisation in maize. Proc. Natl. Acad. Sci. U.S.A., 34, 36-42.

SMITH, S. G. 1962. Chromosomal polymorphism and interrelationship among bark weevils of the genus Pissodes Germar, an amendment. Nucleus, 5, 65-66.

SMITH, S. G. AND TAKENOUCHI, Y. 1962. A unique incompatibility system in a hybrid species. Science, 138, 36-37.
WADE, M. J., PATTERSON, H., CHANG, N. W. AND JOHNSON, N. A. 1994. Postcopulatory, prezygotic isolation in flour beetles. Heredity, 72, 163-167.

WENDEL, J. F., EDWARDS, M. D. AND STUBER, C. W. 1987. Evidence for multilocus genetic control of preferential fertilisation in maize. Heredity, 58, 297-301.

ZIMMERING, S., SANDLER, L. AND NICOLETTI, B. 1970. Mechanisms of meiotic drive. Ann. Rev. Genet., 4, 409-436. 